\title{
A Preliminary Investigation of Rapid Depressurization Phenomena Following a Sudden DLOFC in a VHTR
}

Richard C. Martineau

Ray A. Berry

March 2009

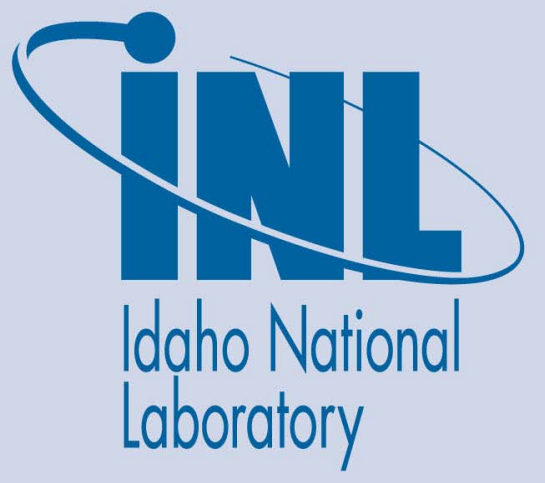

The INL is a U.S. Department of Energy National Laboratory operated by Battelle Energy Alliance 
INL/EXT-09-15634

\title{
A Preliminary Investigation of Rapid Depressurization Phenomena Following a Sudden DLOFC in a VHTR
}

\author{
Richard C. Martineau
}

Ray A. Berry

March 2009

\section{Idaho National Laboratory \\ Advanced Nuclear Energy Systems Department Idaho Falls, Idaho 83415}

http://www.inl.gov

Prepared for the

U.S. Department of Energy

Office of Nuclear Energy

Under DOE Idaho Operations Office

Contract DE-AC07-05ID14517 
Issued by the Idaho National Laboratory, operated for the United States Department of Energy by Battelle Energy Alliance.

NOTICE: This report was prepared as an account of work sponsored by an agency of the United States Government. Neither the United States Government, nor any agency thereof, nor any of their employees, nor any of their contractors, subcontractors, or their employees, make any warranty, express or implied, or assume any legal liability or responsibility for the accuracy, completeness, or usefulness of any information, apparatus, product, or process disclosed, or represent that its use would not infringe privately owned rights. Reference herein to any specific commercial product, process, or service by trade name, trademark, manufacturer, or otherwise, does not necessarily constitute or imply its endorsement, recommendation, or favoring by the United States Government, any agency thereof, or any of their contractors or subcontractors. The views and opinions expressed herein do not necessarily state or reflect those of the United States Government, any agency thereof, or any of their contractors.

Printed in the United States of America. This report has been reproduced directly from the best available copy.

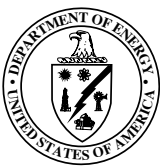




\begin{abstract}
Air ingress has been identified as a potential threat for Very High Temperature gas-cooled Reactors (VHTR). Reactor components constructed of graphite will, at high temperatures, produce exothermic reactions in the presence of oxygen. The danger lies in the possibility of fuel element damage and core structural failure. Previous investigations of air ingress mechanisms have focused on thermal and molecular diffusion, density-driven stratified flow due to hydrodynamic instability, and natural convection. Here, we investigate the possibility of a rapid flow reversal of helium coolant due to a Taylor (rarefaction) wave expansion after a hypothetical sudden depressurized loss of forced cooling (DLOFC) scenario in a VHTR. Concievably, flow reversal of the helium coolant could entrain significant quantities of air into the reactor vessel. Our analysis starts with a one-dimensional shock tube simulation to simply illustrate the development of a Taylor wave with resulting reentrant flow. Then, a simulation is performed of an idealized two-dimensional axisymmetric representation of the lower plenum of General Atomics GT-MHR subjected to a hypothetical catastrophic break of the hot duct. Analysis shows the potential for significant and rapid flow reversal into the reactor vessel in the case of a large break in the cooling system.
\end{abstract}




\section{Contents}

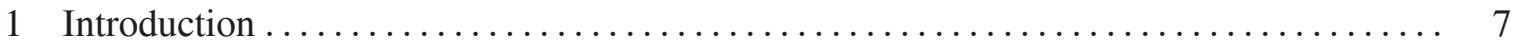

2 Axisymmetric Governing Equations ................................ 9

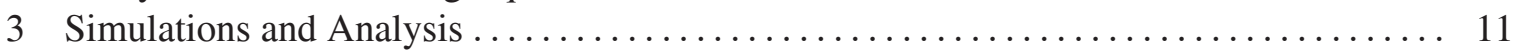

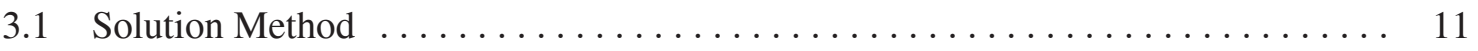

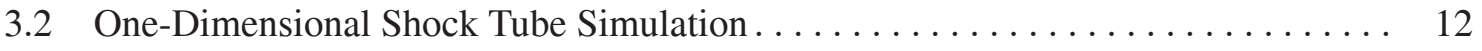

3.3 Axisymmetric Lower Plenum DLOFC Simulation $\ldots \ldots \ldots \ldots \ldots \ldots \ldots \ldots \ldots . \ldots \ldots$

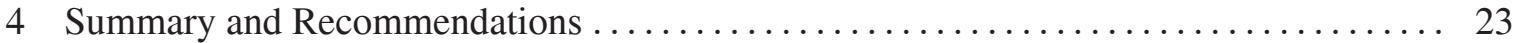

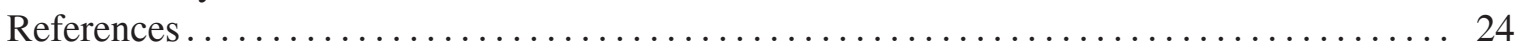




\section{Figures}

1 Shock tube finite element mesh and initial conditions. . . . . . . . . . . . . . . . 12

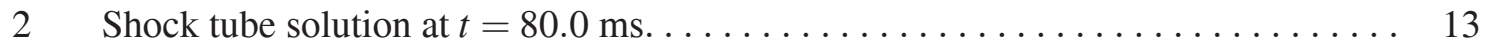

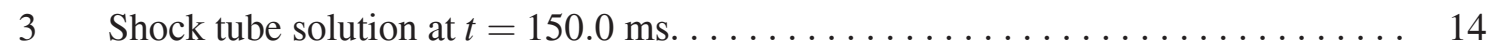

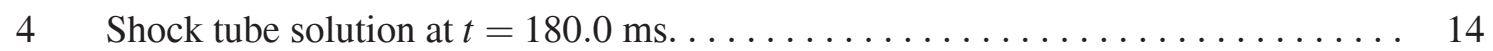

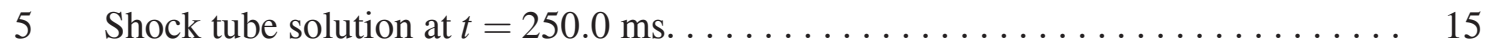

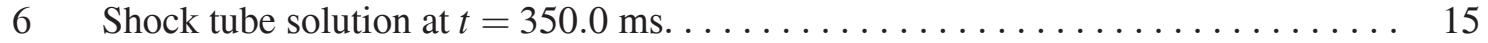

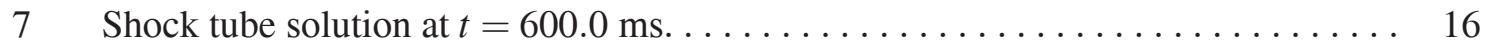

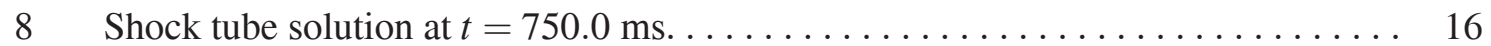

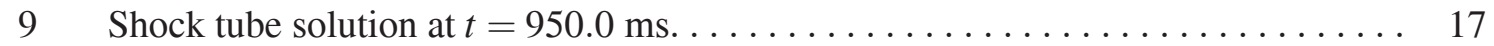

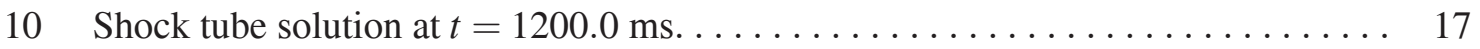

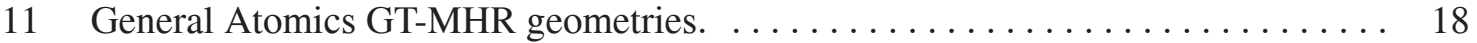

12 Triangular finite element mesh for VHTR lower plenum domain. . . . . . . . . . . 19

13 Lower plenum pressure and temperature distribution at $t=196.4 \mathrm{~ms} \ldots \ldots \ldots \ldots 20$

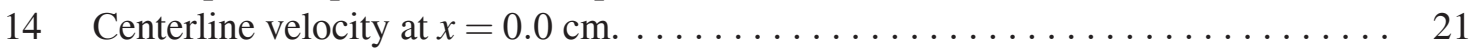

$15 u$-component of velocity near the hot duct break at the approximate moment of

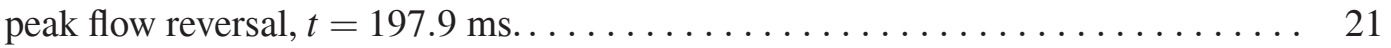




\section{Introduction}

All of the Very High Temperature gas-cooled Reactor (VHTR) concepts currently being considered for the Next Generation Nuclear Plant (NGNP) are designed with a high-level of passive safety. In terms of core criticality, these reactors are designed to survive a loss of forced cooling for both pressurized and depressurized events without needing complex emergency forced cooling systems. The most catastrophic of these hypothetical events is the Depressurized Loss of Forced Cooling (DLOFC) accident based on a complete double ended guillotine break of the counter-flow inlet and outlet gas manifold (hot duct) between the pressure vessel and the power conversion unit. While a complete break in the hot duct is considered unlikely, the consequences of such a catastrophic event warrant investigation. One of the major consequences of this event in a VHTR is the possibility of massive air ingress into the core and structural components. Oxygen in sufficiently high concentration poses a serious threat for high temperature graphite reflected and moderated reactors (both prismatic and pebble bed designs) because of graphite exothermic oxidation reaction (burning) and surface corrosion. Severe air ingress in VHTRs [9] can potentially cause fuel element damage by corrosion, corrosive attack of the graphite core support structure until failure, formation of burnable gas mixtures, and formation of graphite aerosols resulting in the release of fission products. The United States Nuclear Regulatory Commission has identified this event in the NGNP Phenomena Identification and Ranking Tables (PIRTs) [3] and has stated that:

"The most significant phenomena (those assigned an importance rank of "high" with the corresponding knowledge level of "low" or "medium") in the thermal-fluids area include primary system heat transport phenomena which impact fuel and component temperatures, reactor physics phenomena which impact peak fuel temperatures in many events, and postulated air ingress accidents that, however unlikely, could lead to major core and core support damage."

Several mechanisms for air ingress in potential VHTR DLOFC events have been investigated, including molecular and thermal diffusion, density-driven stratified flow due to hydrodynamic instability, and natural convection. Molecular and thermal diffusion [8, 12] occurs after reactor depressurization where it is assumed that only helium occupies the core, the upper and lower plenums, and the gas manifold between the break and the reactor vessel. Outside of the break and the reactor vessel resides cool heavy air. During this phase of the accident scenario, air from the containment is mainly transported to the reactor by molecular diffusion. The volume fraction of air in the core and upper plenum of the reactor gradually increases until the buoyancy force is large enough to initiate natural convection $[8,2]$. It is assumed the density-driven stratified flow behavior $[13,10]$ will occur when a major break in the hot duct unchokes and the outgoing helium flow from the vessel and the incoming air flow into the vessel are governed by the density differences between the outgoing helium and incoming air. After the reactor vessel fills in this manner to a critical point, natural convection becomes the dominant flow feature.

Diffusion, stratification, and natural convection are viable mechanisms for investigation of air ingress into the system over long time scales. However, simulation of these mechanisms do not capture the dynamics of the flow at very short time scales, in particular, the rapid flow reversal 
resulting from a Taylor wave (a type of rarefaction wave) expansion exiting a hypothetical break in the hot duct after a sudden DLOFC event. This wave phenomena would precede in time any of the above mentioned air ingress mechanisms and would occur before the depressurization event ended. In this report, we will investigate this rapid flow reversal mechanism of air ingress. First, we will briefly describe the governing equations and solution method employed for our analysis. Then, two axisymmetric simulations will be presented. The first will be a shock tube problem with the downstream boundary open to ambient pressure. The simulation will be carried out far enough in time to allow for flow reversal from the downstream boundary. This simulation provides an animated illustration of how a Taylor wave is generated with the resulting flow reversal. Finally, a simplified two-dimensional axisymmetric simulation of a double ended guillotine break of the helium hot duct into the lower plenum of an VHTR is presented. The simulation will be also carried out far enough in time to allow flow reversal from the ambient surroundings. This report ends with a summary and recommendation section containing recommendations for further investigations. 


\section{Axisymmetric Governing Equations}

For this analysis, we are primarily interested in strong pressure wave propagation where large pressure gradients and shocks will be present in the flow. Neglecting viscous and thermal diffusion effects, the conservative form of the Euler equations are employed. Expressed in two-dimensional axisymmetric space-time coordinates $(x, r, t)$, these equations are the conservation of mass equation,

$$
\frac{\partial \rho}{\partial t}+\frac{\partial \rho u}{\partial x}+\frac{1}{r} \frac{\partial r \rho v}{\partial r}=0
$$

the balance of momentum in the axial $x$-direction,

$$
\frac{\partial \rho u}{\partial t}+\frac{\partial\left(\rho u^{2}+P\right)}{\partial x}+\frac{1}{r} \frac{\partial r \rho u v}{\partial r}=0
$$

the balance of momentum in the radial $r$-direction,

$$
\frac{\partial \rho v}{\partial t}+\frac{\partial \rho u v}{\partial x}+\frac{1}{r} \frac{\partial r\left(\rho v^{2}+P\right)}{\partial r}=0
$$

and the conservation of total energy equation,

$$
\frac{\partial \rho e_{t}}{\partial t}+\frac{\partial \rho u h_{t}}{\partial x}+\frac{1}{r} \frac{\partial r \rho v h_{t}}{\partial r}=0
$$

In equations (1)-(4), the variable $\rho$ is density, $u$ and $v$ are the components of the velocity vector $\vec{u}$ in the axial $x$ (axis of symmetry) and radial $r$ directions, respectively, $P$ is the thermodynamic pressure, and $e_{t}$ is the specific total energy. The conserved variables, $\rho u$ and $\rho v$ are the momentum components and $\rho e_{t}$ is the total energy. The specific total enthalpy, $h_{t}$ in equation (4), is defined by

$$
h_{t}=\frac{\rho e_{t}+P}{\rho} .
$$

The ideal gas equation of state is employed in this analysis,

$$
P=(\gamma-1) \rho e=\rho R_{c} T
$$

where $e$ is the specific internal energy, $\gamma$ is the ratio of specific heats, and $R_{C}$ is the gas constant per unit mass of the fluid. As temperature $T$ and internal energy $e$ are not specific solution variables 
of equations (1)-(4), the ideal gas equation of state is more commonly expressed in terms of the conserved variables,

$$
P=(\gamma-1)\left(\rho e_{t}-\frac{\rho \vec{u} \cdot \rho \vec{u}}{2 \rho}\right) \quad \text { and } \quad T=\frac{1}{c_{\nu} \rho}\left(\rho e_{t}-\frac{\rho \vec{u} \cdot \rho \vec{u}}{2 \rho}\right)
$$

where $c_{v}$ is the specific heat at constant volume. 


\section{Simulations and Analysis}

A Taylor wave is defined as a rarefaction expansion wave that brings the flow to rest by isentropic expansion, usually following a compression wave (shock). The wave is composed of a pressure gradient adverse to the direction of the flow velocity. Taylor waves are a common occurrence and are generated in explosions, all types of firearms, combustion engines (a two-stroke engine's operation depends on a Taylor wave to draw the fuel-air mixture into the combustion chamber), pneumatic tools, etc. The wave was first mathematically formulated independently by both Taylor [16] and Sedov [14] at about the same time though Sedov was unable to publish his results until much later. A Taylor wave can be formed from a reflection of a rarefaction wave from an axis of symmetry or a solid surface. A rarefaction wave is defined as an expansion wave accelerating the flow from a high pressure region into a lower pressure state. Stanyukovich [15] gives an excellent description and mathematical formulation of how a Taylor wave is formed from a rarefaction wave reflection. For a flow configuration the size of a VHTR reactor vessel, flow reversal generated from a Taylor wave is a relatively short time scale event, on the order of one second.

This section begins with a brief description of the solution method. Then, two rapid depressurization simulations performed on axisymmetric domains are presented. The first will be the classic Riemann shock tube problem with the downstream boundary open to ambient pressure. The simulation will be carried out far enough in time to allow flow reversal from the downstream boundary. This simple simulation will provide an animated illustration of the Taylor wave generation and resulting flow reversal. Finally, a simplified two-dimensional axisymmetric simulation of a double ended guillotine break of the helium gas manifold into the lower plenum of a VHTR is presented.

\subsection{Solution Method}

The conservative solver employed in this study is the PCICE-FEM scheme [6]. The PCICE-FEM scheme is a finite element method (FEM) spatial discretization of the Pressure-Corrected Implicit Continuous-fluid Eulerian (PCICE) algorithm. The PCICE algorithm defines the temporal discretization and hydrodynamic coupling procedure for the PCICE-FEM scheme. It is an semiimplicit, mass-momentum coupled pressure-based scheme. The governing hydrodynamic equations for this scheme are the conservative form of the balance of momentum equations, mass conservation equation, and the total energy equation. An operator splitting process is performed along explicit and implicit operators of the temporal discretization to render the PCICE-FEM scheme in the class of predictor-corrector schemes. The complete set of governing equations in the PCICEFEM scheme is cast in this form, an explicit predictor step and a semi-implicit pressure-correction step with an elliptic pressure Poisson solution coupling the predictor-corrector steps. The result of this predictor-corrector formulation is that the pressure Poisson equation in the PCICE-FEM scheme is provided with sufficient internal energy information to avoid iteration. In the PCICEFEM code employed here, a generalized Flux-Corrected Transport (FCT) method [17, 5] is incorporated to capture shocks and to provide a monotonic solution. 


\subsection{One-Dimensional Shock Tube Simulation}

The shock tube (or Riemann problem) provides, in one spatial dimension, all of the compressible flow features that are present during a hypothetical DLOFC event in an VHTR. The Riemann problem also has the added benefit of an available analytical solution [11]. The simulation presented here is designed to illustrate how a Taylor expansion wave can be generated from a sudden depressurization and result in a rapid flow reversal.

The PCICE-FEM code we employed here solves equations (1)-(4). Thus, the one-dimensional shock tube domain is represented on a two-dimensional mesh, a portion of which is shown in Figure 1. Axisymmetric integration essentially requires that the computational mesh be integrated $2 \pi r$ radians around the axis of symmetry, the $x$-axis. The mesh shown in Figure 1 represents a circular pipe of constant cross-sectional area with a radius of $0.4 \mathrm{~m}$ and the $x$-axis $(r=0.0 \mathrm{~m})$ being the centerline of the pipe. What defines this problem mathematically as one-dimensional are
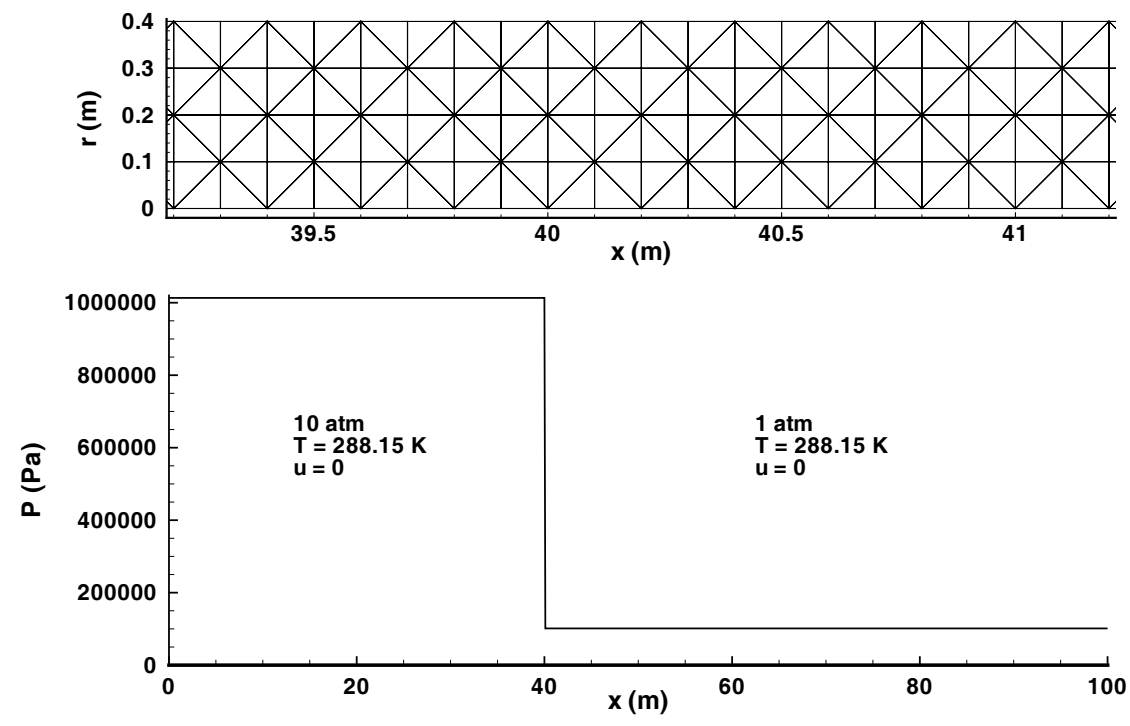

Figure 1. Shock tube finite element mesh and initial conditions.

the initial and boundary conditions. Figure 1 shows the initial conditions for pressure, temperature, and velocity in this problem. The initial states are left of $x=40 \mathrm{~m}$ with 10 atmospheres of pressure $(1.01325 \mathrm{MPa})$ at a temperature of $288.15 \mathrm{~K}$. Right of $x=40 \mathrm{~m}$ the domain is initialized to ambient conditions $(P=101.325) \mathrm{kPa}$ and $T=288.25 \mathrm{~K}$. The boundary conditions are free-slip solid wall conditions (the normal velocity at the wall is specified to be zero) for the top and bottom walls at $r=0.0 \mathrm{~m}, r=0.4 \mathrm{~m}$, respectively. The boundary condition at $x=0.0 \mathrm{~m}$ can be thought of as a capped end of the tube and it is also given a free-slip solid wall condition. The boundary condition at $x=100.0 \mathrm{~m}$ is open to ambient conditions. This domain and initial-boundary conditions could be thought of as a one-dimensional tank of air at room temperature that is about to suddenly depressurize into a long room. The material properties are that of air. The following pressure and 
velocity plots taken at various times in the simulation are plots of centerline values at $r=0.0 \mathrm{~m}$. The red lines of the pressure plots shown in Figures 2-10 indicates ambient pressure level of 1 atmosphere $P_{\text {atm }}$. The red lines of the velocity plots shown in Figures 8-10 depict the zero velocity level.

Figure 2 shows the pressure and velocity solution $80 \mathrm{~ms}$ after depressurization begins. At

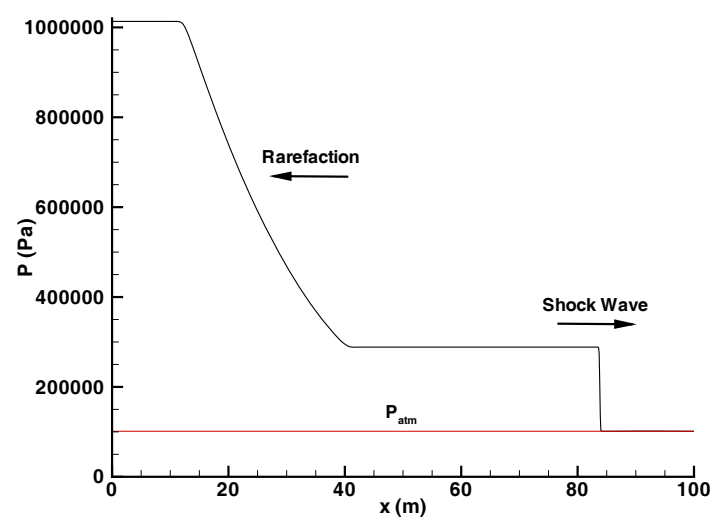

(a) Pressure solution.

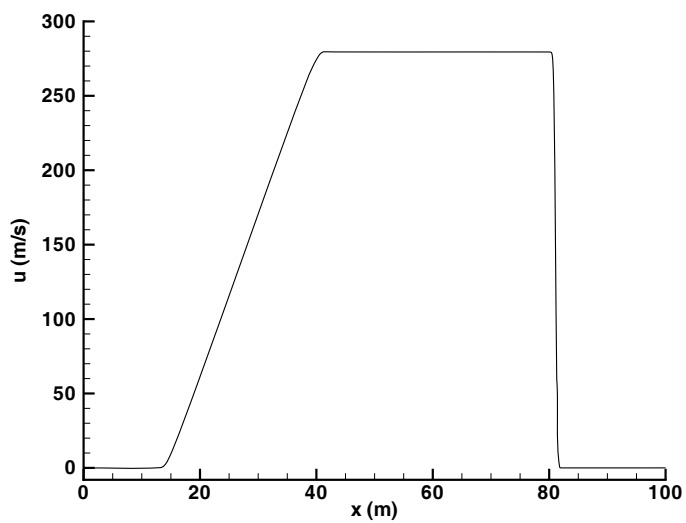

(b) Velocity solution.

Figure 2. Shock tube solution at $t=80.0 \mathrm{~ms}$.

the time of $t=80.0 \mathrm{~ms}$, we see the classic Riemann solution for the shock tube being formed. Propagating to the right in Figure 2(a) is the shock wave, which compresses the air in front of the shock causing a known jump in pressure. Propagating to the left is a depressurization wave known as a rarefaction wave because the air in the high pressure region is being rarefied by an expansion wave. In Figure 2(b) we see how these two pressure waves disturb the initially static flow field. Although these pressure waves propagate in two different directions, the flow is to the right as indicated by positive values of velocity.

Figure 3(a) shows the shock tube approximate pressure solution at $t=150.0 \mathrm{~ms}$. The shock wave has propagated out of the domain and the rarefaction wave is in the process of reflecting off of the solid wall back boundary. We can see the reflection region extending from $x=0.0 \mathrm{~m}$ to approximately $x=14.0 \mathrm{~m}$. In this reflection region, pressure is rapidly decreasing. Figure 3(b) shows the shock tube velocity solution, which is positive over the entire domain indicating the air is moving out of the domain. Intuitively, we can predict that the pressure in this system must drop as the mass and energy of the system are both decreasing. In the region where $x>40.0 \mathrm{~m}$, the velocity is constant and, thus, so is the pressure. In the region from $0.0 \leq x \leq 40.0 \mathrm{~m}$, the velocity is increasing from left to right. We can think of this portion of the flow field as being in "tension" and will be the region of rapidly decreasing pressure. At this simulation time of $t=150.0 \mathrm{~ms}$, we see that the pressure in the rarefaction reflection region has dropped more than $400 \mathrm{kPa}$. Figure 4 illustrates the pressure/velocity solution at $t=180.0 \mathrm{~ms}$. Here, the rarefaction wave reflection region is growing in length and rapidly decreasing in pressure. 


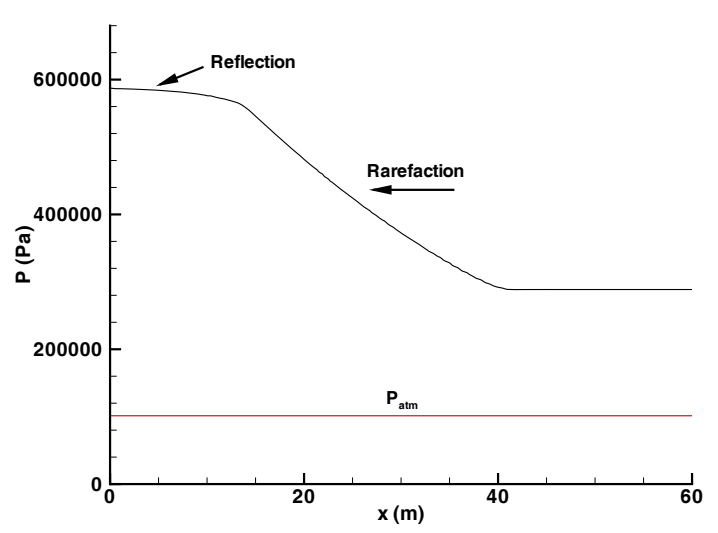

(a) Pressure solution.

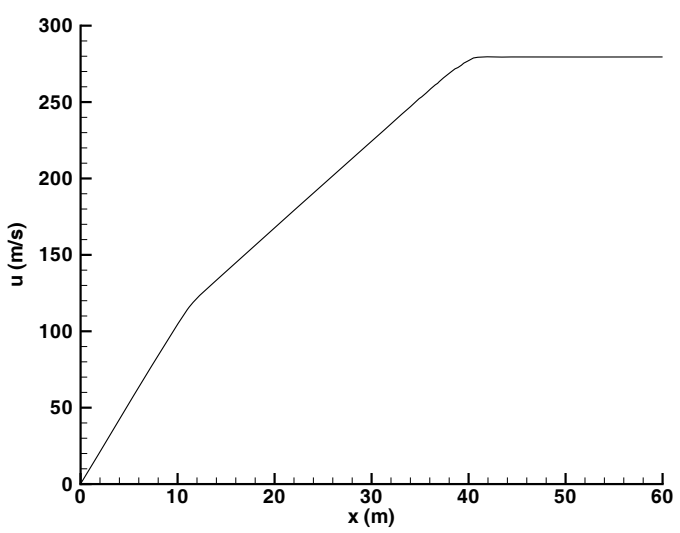

(b) Velocity solution.

Figure 3. Shock tube solution at $t=150.0 \mathrm{~ms}$.

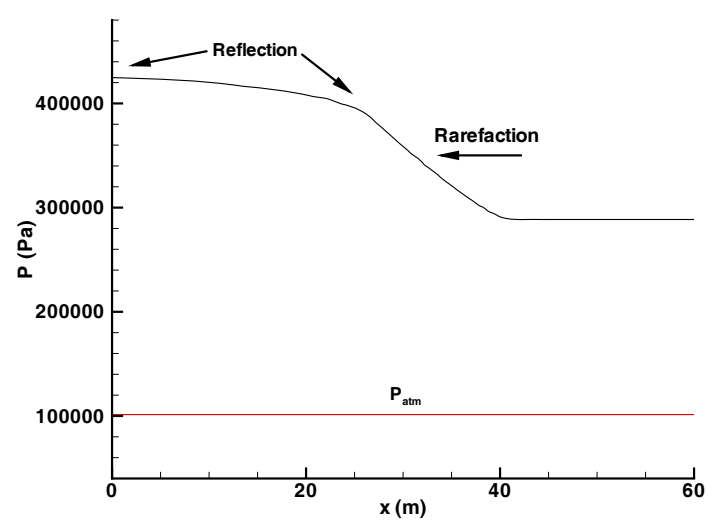

(a) Pressure solution.

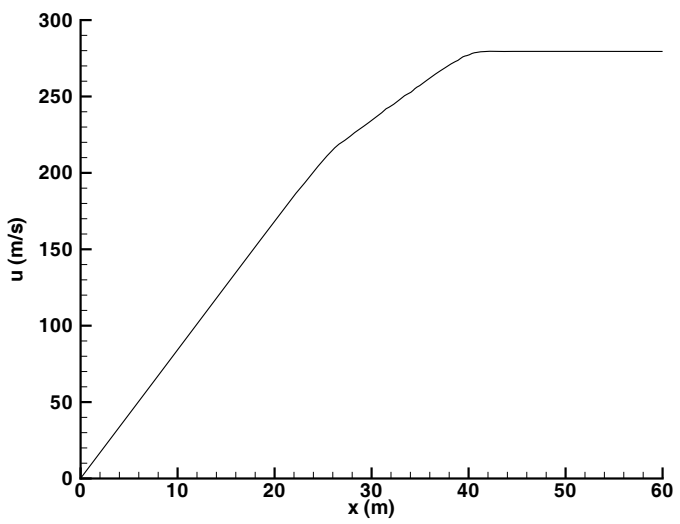

(b) Velocity solution.

Figure 4. Shock tube solution at $t=180.0 \mathrm{~ms}$.

By the solution time of $t=250.0 \mathrm{~ms}$, the pressure in the rarefaction wave reflection region, shown in Figure 5(a), has decreased to the point where a Taylor expansion wave has formed. The pressure gradient in the Taylor wave region, approximately extending from $x=40.0 \mathrm{~m}$ to $x=68.0$ $\mathrm{m}$, is adverse to the direction of flow, shown in Figure 5(b). As a result, we begin to see the velocity significantly decreasing in the domain from about $x=0.0 \mathrm{~m}$ to $x=68.0 \mathrm{~m}$. Figure 6 shows the trend depicted in Figure 5 continuing at a solution time of $t=350.0 \mathrm{~ms}$. The pressure behind the Taylor wave continues drop and is approaching the atmospheric pressure line, as shown in Figure 6(a). The leading edge of the Taylor has just passed $x=80.0 \mathrm{~m}$. The deceleration of the velocity field, shown in Figure 6(b), continues. The pressure in the Taylor wave region must 


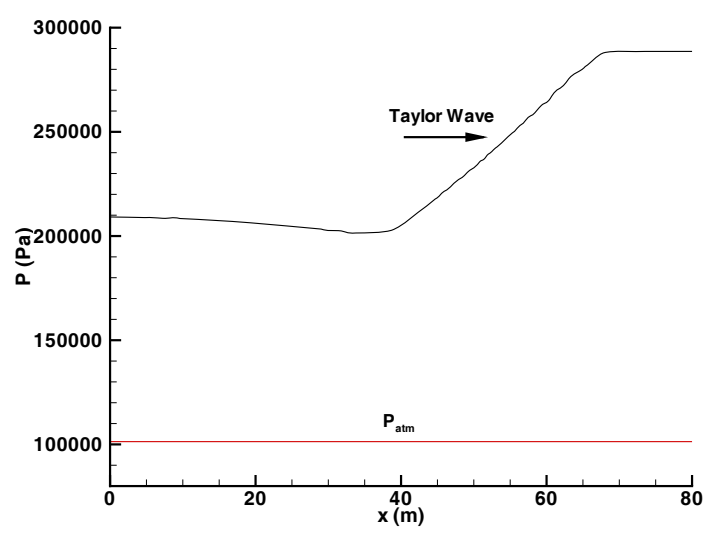

(a) Pressure solution.

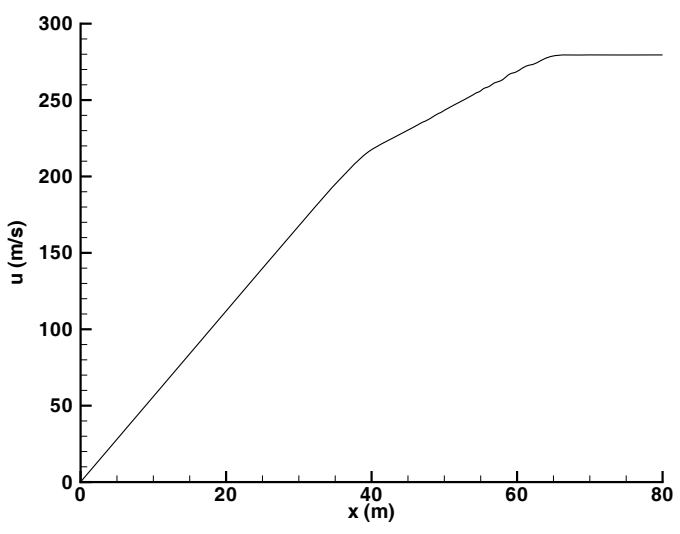

(b) Velocity solution.

Figure 5. Shock tube solution at $t=250.0 \mathrm{~ms}$.

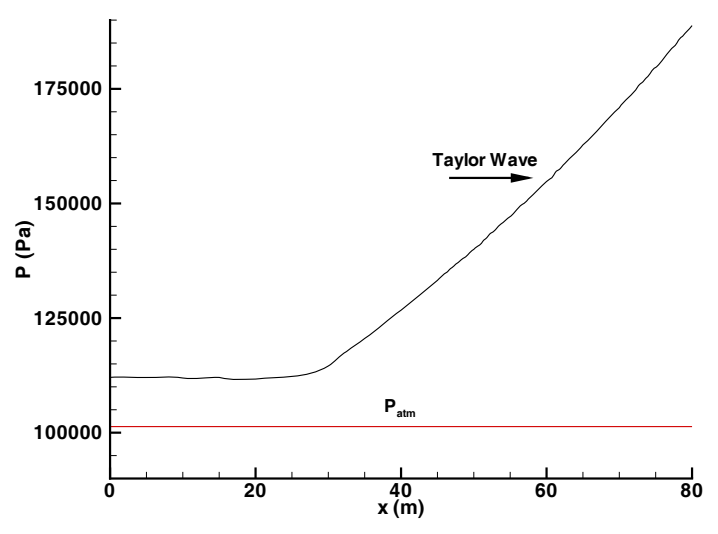

(a) Pressure solution.

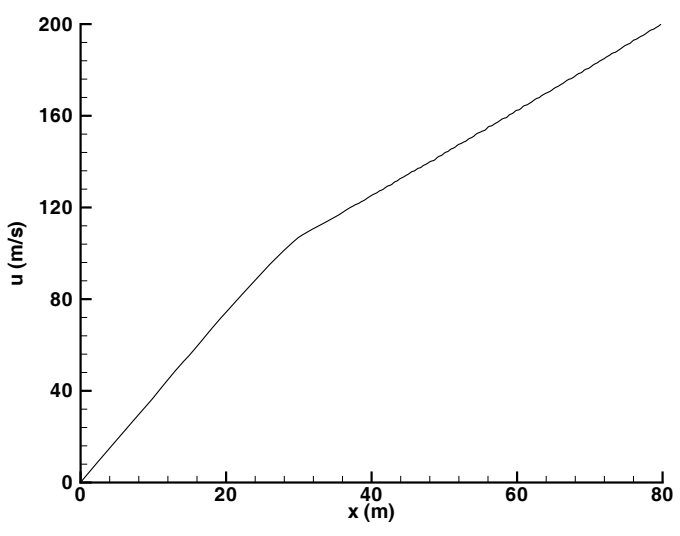

(b) Velocity solution.

Figure 6. Shock tube solution at $t=350.0 \mathrm{~ms}$.

continue to drop as long the flow velocity is positive. Figure 7(a) is the pressure and velocity distribution at simulation time of $t=600.0 \mathrm{~ms}$. At this point in the solution, the entire domain pressure field is below atmospheric pressure and Figure 7(b) shows that peak velocity has dropped in half. Thus, flow reversal will have to take place shortly.

Figures 8-10 illustrate the flow reversal phase of the shock tube simulation. Flow reversal in this simulation began approximately at the time $t=735 \mathrm{~ms}$. With $t=750.0 \mathrm{~ms}$ in Figure $8(\mathrm{a})$, we see the beginnings of the flow reversal in the pressure field with a reverse shock (pressure) wave traveling in from the right-hand boundary at approximately $x=69.0 \mathrm{~m}$. Note that the velocity 


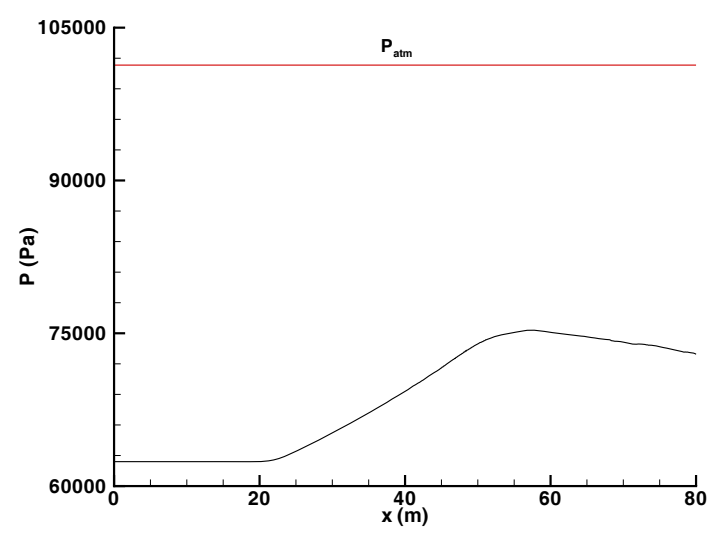

(a) Pressure solution.

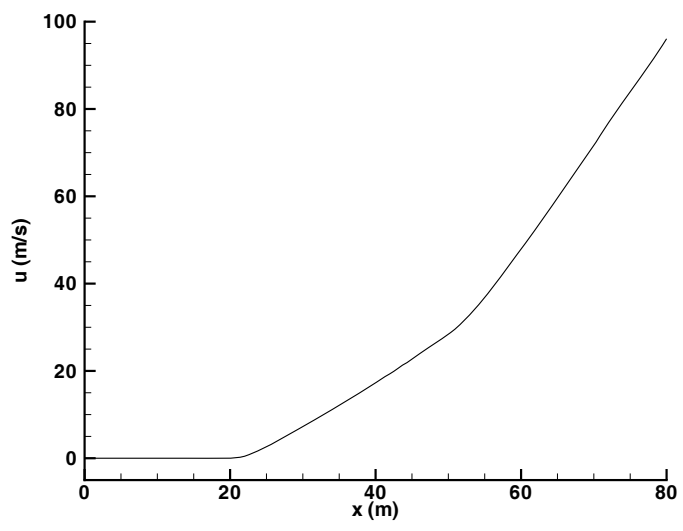

(b) Velocity solution.

Figure 7. Shock tube solution at $t=600.0 \mathrm{~ms}$.

field of Figure 8(b) does not transition to negative values until approximately $x=78.0 \mathrm{~m}$, meaning that the pressure wave is propagating upstream against a subsonic flow between $x=69.0 \mathrm{~m}$ and $x=78.0 \mathrm{~m}$.

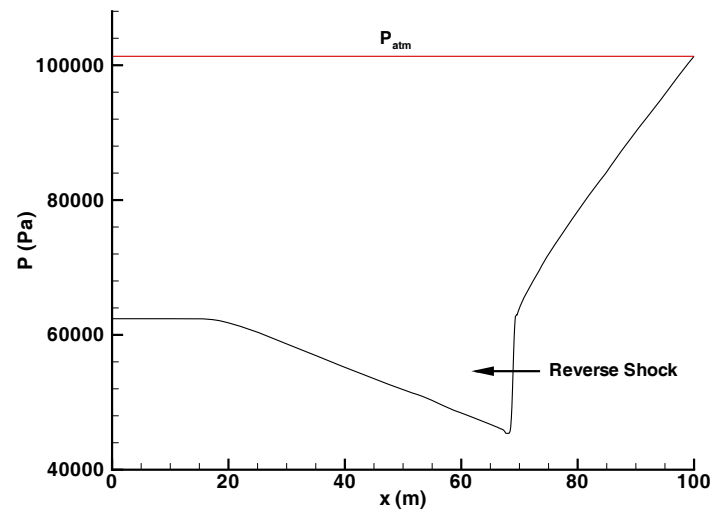

(a) Pressure solution.

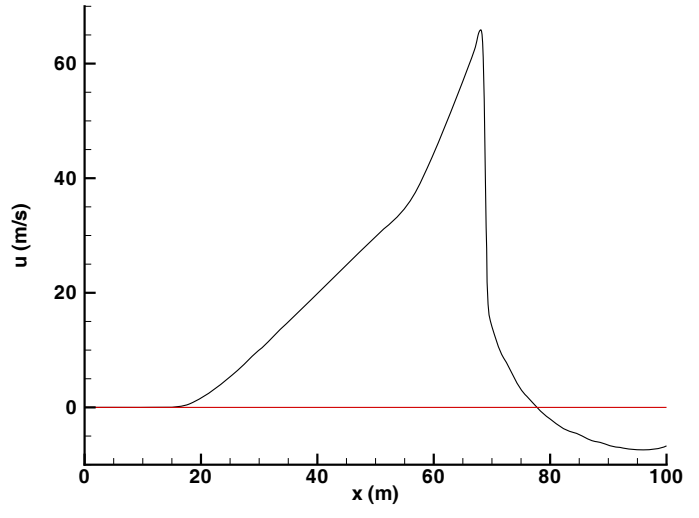

(b) Velocity solution.

Figure 8. Shock tube solution at $t=750.0 \mathrm{~ms}$.

The pressure and velocity distributions at the simulation time of $t=950.0 \mathrm{~ms}$ are plotted in Figure 9. Now we see that most of the flow field is in a reverse flow situation with a peak inflow velocity of nearly $80.0 \mathrm{~m} / \mathrm{s}$, as shown in Figure 9(b). In Figure 9(a), we see that the pressure directly in front of the reverse flow shock has dropped below $48 \mathrm{kPa}$. Again, we see that the entire pressure field is below the atmospheric pressure line. 


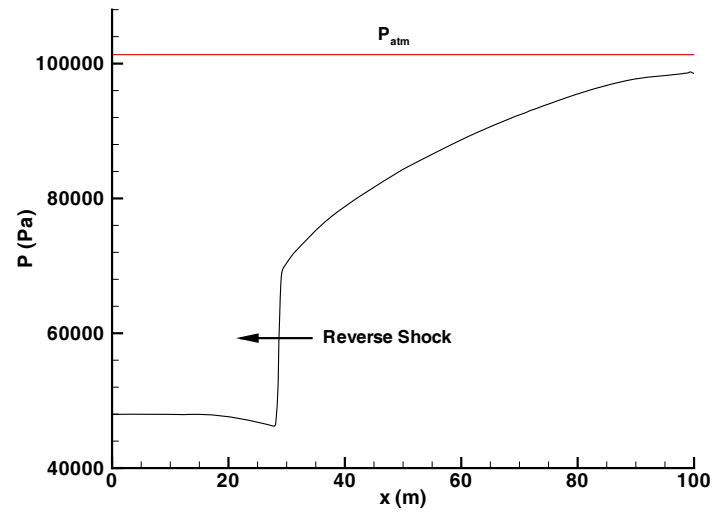

(a) Pressure solution.

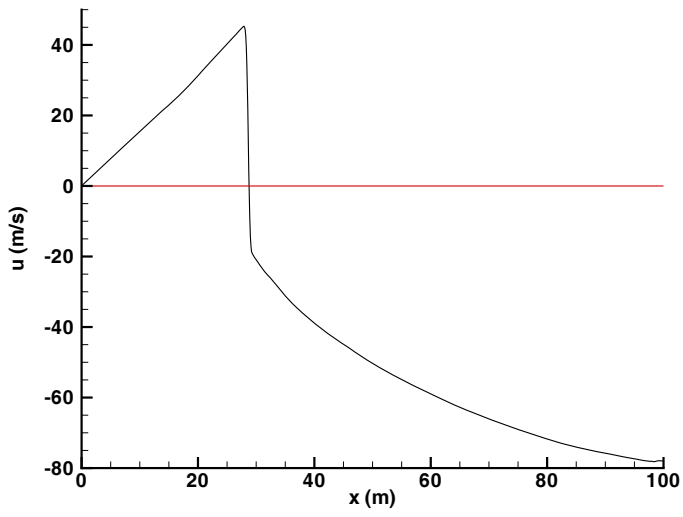

(b) Velocity solution.

Figure 9. Shock tube solution at $t=950.0 \mathrm{~ms}$.

The final shock tube plot is shown in Figure 10 for a simulation time of $t=1200.0 \mathrm{~ms}$. Figure 10(a) indicates that the reverse flow shock has just impacted the solid wall back boundary and has formed yet another shock that is propagating against the direction of the flow velocity. By this point in the simulation, the entire velocity field in Figure 10(b) is negative.

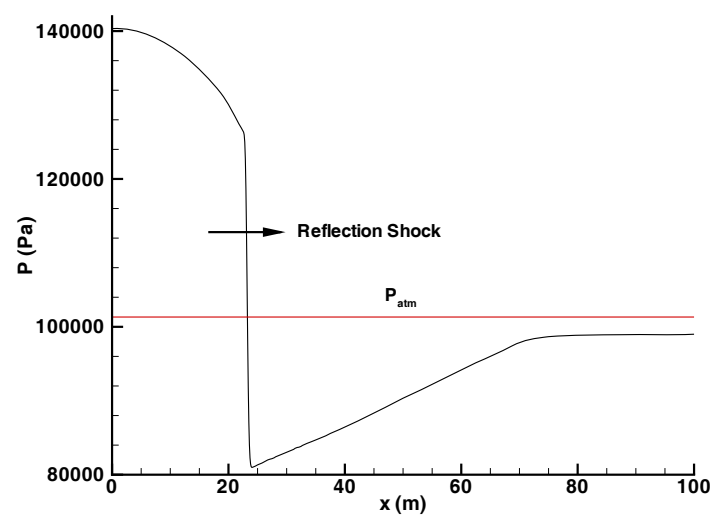

(a) Pressure solution.

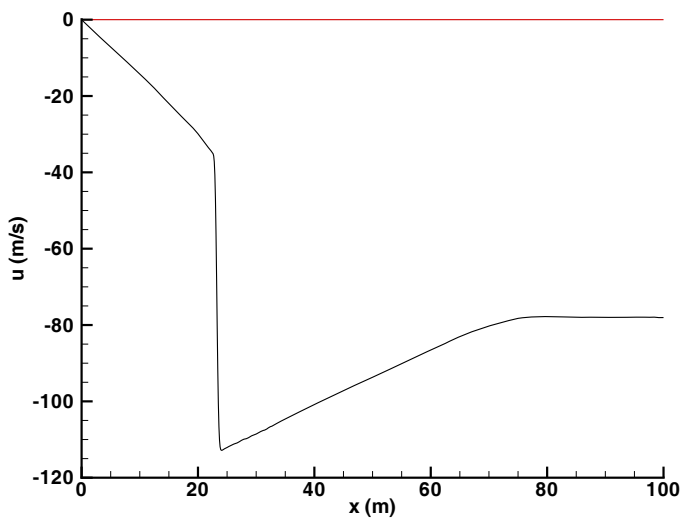

(b) Velocity solution.

Figure 10. Shock tube solution at $t=1200.0 \mathrm{~ms}$.

This shock tube simulation should give an intuitive understanding of Taylor wave formation resulting in rapid flow reversal from a sudden depressurization. Obviously, this is a short time scale event relative to molecular and thermal diffusion, density-driven stratified flow, and natural convection. The Taylor wave expansion would precede the occurrence of these other mechanisms 
in a sudden depressurization event. The above shock tube domain was a prescribed $100.0 \mathrm{~m}$ long. Yet, we see pressure waves traveling the length of the shock tube and back again in less than $1.2 \mathrm{~s}$.

\subsection{Axisymmetric Lower Plenum DLOFC Simulation}

The second simulation example is of a two-dimensional, axisymmetric representation of a sudden break in the hot duct near the lower plenum of a VHTR. The purpose of simulating this twodimensional lower plenum geometry is to provide insight of the expected magnitude of the flow reversal velocities associated with a full three-dimensional VHTR hot duct failure. Figure 11(a) is a cutaway illustration of the General Atomics Gas Turbine-Modular Helium Reactor (GT-MHR) [1] geometry. To make this geometry more amendable to two-dimensional modeling, all components except the reactor pressure vessel, annular core, and hot duct are ignored. With axisymmetric integration, flow boundaries are integrated around the axis of rotation. Thus, for this simulation, the gas manifold is moved to the extremum of the lower plenum. The two-dimensional geometry is shown in Figure 11(b).

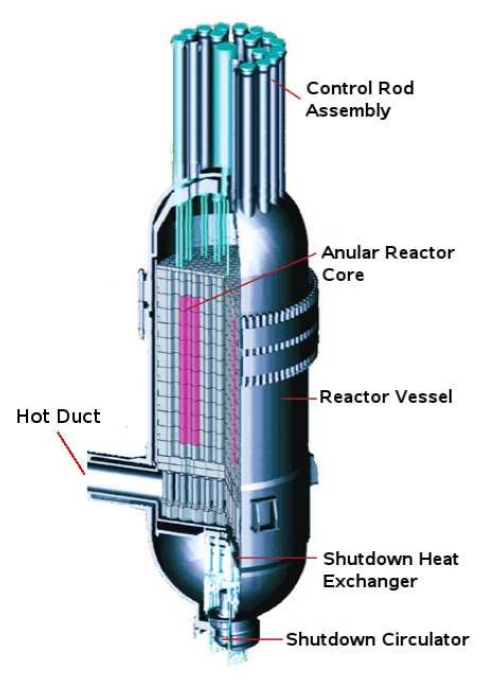

(a) Schematic of GT-MHR, Courtesy of General Atomics.

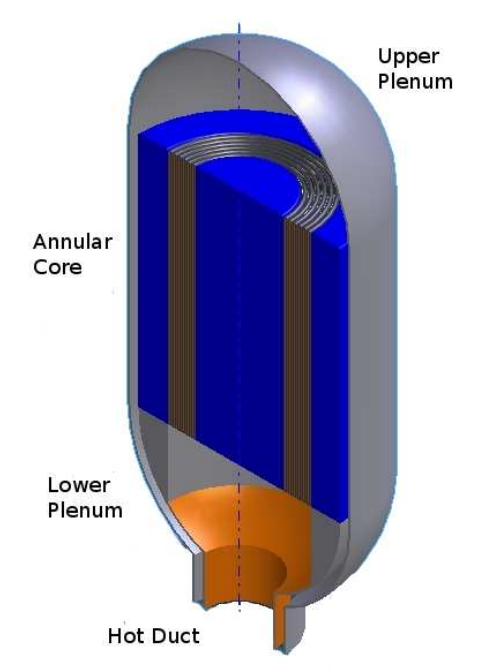

(b) Two-dimensional axisymmetric representation of the GT-MHR.

Figure 11. General Atomics GT-MHR geometries.

Imagine the lower plenum of Figure 11(b) with a small length of hot duct open to a region of expansion. Figure 12 illustrates a simple triangular mesh used to represent the interior of the lower plenum of the GT-MHR. The lower plenum extends from $x=73.0 \mathrm{~cm}$ to $x=413.0 \mathrm{~cm}$ with a radius of $340.0 \mathrm{~cm}$. An arbitrarily chosen length of the hot duct ranges from $x=0.0 \mathrm{~cm}$ to $x=73.0 \mathrm{~cm}$. The hypothetical break in the hot duct is located at $x=0.0 \mathrm{~cm}$. This axisymmetric mesh closely matches the volume of the lower plenum region of the GT-MHR geometry[1]. With the correct 


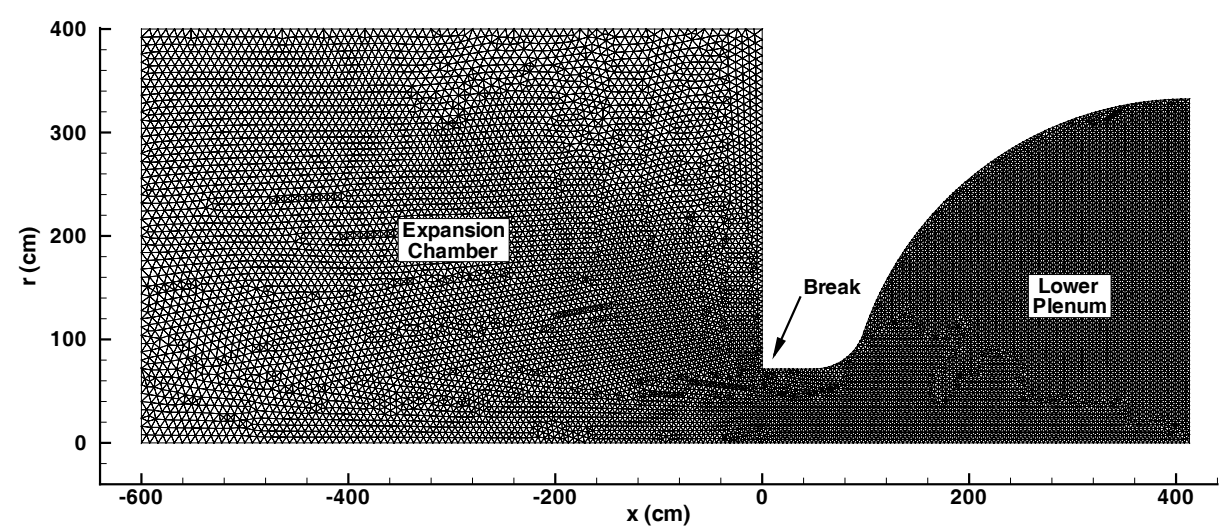

Figure 12. Triangular finite element mesh for VHTR lower plenum domain.

hot duct diameter, we expect the flow velocities in this simulation to be representative of an actual event. An expansion chamber is included in the mesh to allow for some multi-dimensional effects near the break during the flow reversal.

The boundary and initial conditions for the domain shown in Figure 12 are as follows. The back wall of the plenum is located at $x=413.0 \mathrm{~cm}$. It is not open to the core for this simple demonstration. Thus, the back wall is specified to be free-slip solid wall. The curved surface of the lower plenum up to the break, the side of the expansion chamber located at $x=0.0 \mathrm{~cm}$, and the top of the expansion chamber at $r=400.0 \mathrm{~cm}$ are all specified to be free-slip solid walls. By definition, the axis of symmetry $(r=0.0 \mathrm{~cm})$ is a free-slip solid wall. The left boundary located at $x=-600.0 \mathrm{~cm}$ is defined as a flow exit with reverse flow capability [7]. The specified pressure at this boundary (when the flow is not supersonic) is $P=100.0 \mathrm{kPa}$. The specified temperature on this boundary in the case of flow reversal is $T=773.15 \mathrm{~K}$. This temperature is arbitrarily defined in this simulation. A more accurate determination of the flow reversal temperature will require a full three-dimensional reactor containment simulation. The initial conditions for the lower plenum $(0.0 \leq x \leq 413.0 \mathrm{~cm})$ are pressure, temperature, and velocity of $P=7.0 \mathrm{MPa}, T=1273.15 \mathrm{~K}$, and $\vec{u}=0.0 \mathrm{~cm} / \mathrm{s}$, respectively. In the expansion chamber, the initial conditions are pressure, temperature, and velocity of $P=100.0 \mathrm{kPa}, T=773.15 \mathrm{~K}$, and $\vec{u}=0.0 \mathrm{~cm} / \mathrm{s}$, respectively. The working fluid for this simulation is ideal helium gas.

An instant before the hypothetical hot duct failure, the initial conditions in the lower plenum are the initial stagnation conditions (which will decrease over time during plenum depressurization) of this system. At a stagnation temperature of $T=1523.15 \mathrm{~K}$, the local sound speed is $209,934 \mathrm{~cm} / \mathrm{s}$, indicating that the choke velocity magnitude near the break will be quite high. A rough estimate bounding calculation using the steady one-dimensional variable area isentropic flow relations for an ideal gas [18] gives a maximum choking velocity (where the Mach number is $M=1.0$ ) of $181,808 \mathrm{~cm} / \mathrm{s}$ (the location of the choke point in the throat is not always precisely determined 
in multi-dimensional flow). This velocity is lower than the sound speed at stagnation conditions due to the cooling of the gas during expansion. The simulated peak flow velocity at the break $(x=r=0.0 \mathrm{~cm})$ is achieved at time $t=2.402 \mathrm{~ms}$ with a value of $194,270 \mathrm{~cm} / \mathrm{s}$, indicating that the choke point is slightly upstream of the break. In our simulation, the isoline for $M=1.0$ inside the hot duct approximately ranges from $20.0 \leq x \leq 40.0 \mathrm{~cm}$ until the flow inside the hot duct unchokes. At the approximate simulation time of $t \approx 101.1 \mathrm{~ms}$, the flow in the hot duct unchokes.

After the flow in the hot duct unchokes, the plenum continues to depressurize until $t \approx 196.4$ ms. At this point in time, the lowest pressure in the lower plenum is achieved, $P=95,790.3$ $\mathrm{Pa}$. Figure 13 contains plots of the pressure and temperature at the simulation time $t=196.4$ ms. In Figure 13(a), we see that the entire pressure field in the plenum is below the expansion

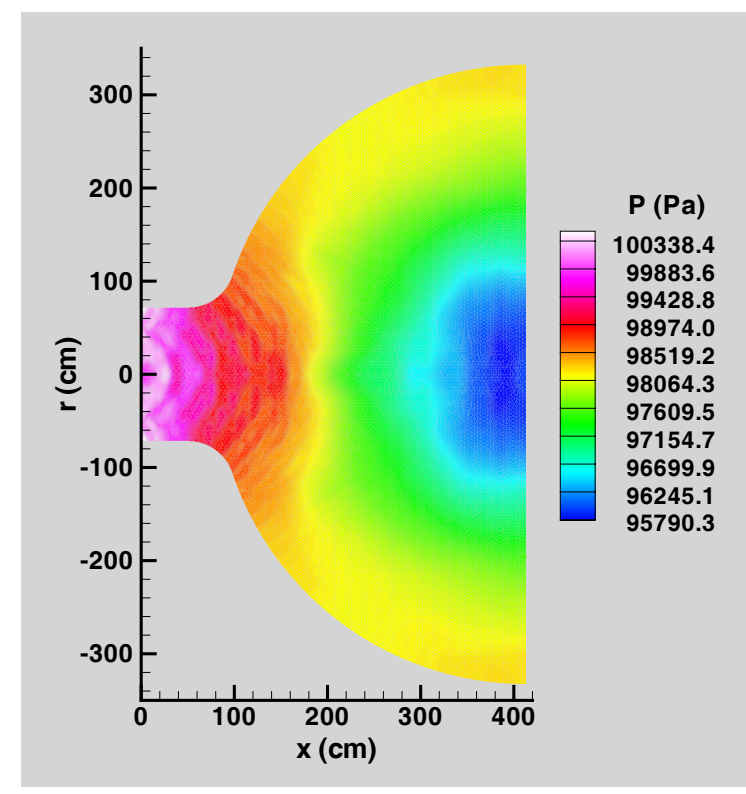

(a) Plenum pressure distribution.

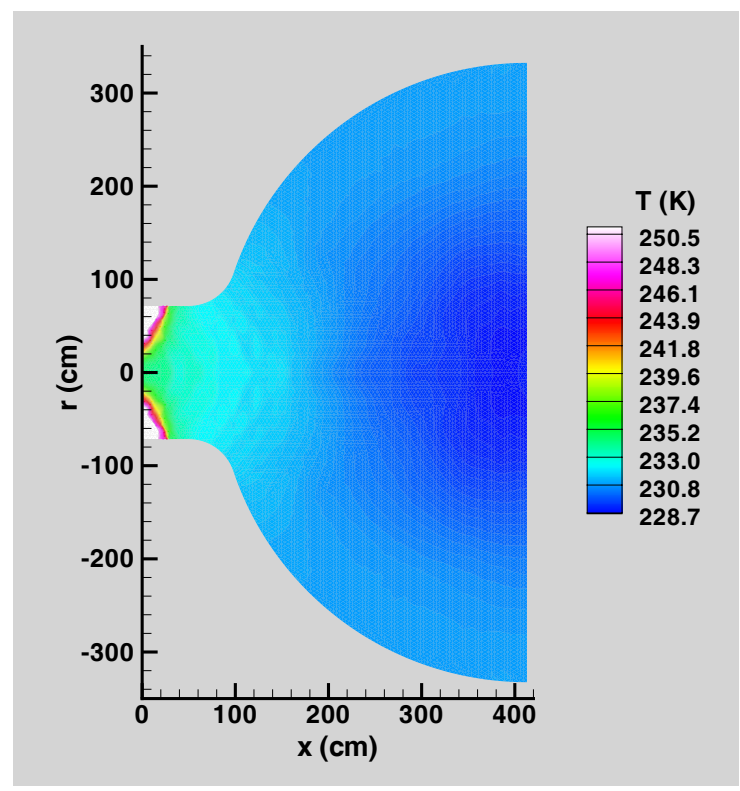

(b) Plenum temperature distribution.

Figure 13. Lower plenum pressure and temperature distribution at $t=196.4 \mathrm{~ms}$.

chamber inlet pressure of $P=100.0 \mathrm{kPa}$. The domain pressure solution exhibits small oscillations due to multi-dimensional effects causing many low-amplitude pressure reflections. Note that the minimum temperature in the plenum, shown in Figure 13(b), has dropped dramatically due to a 70 to 1 expansion.

Figure 14 is a time history plot of centerline $(r=0.0 \mathrm{~cm})$ velocity at the hot duct break $(x=0.0$ $\mathrm{cm}$ ) between the solution times of $160.0 \leq t \leq 500.0 \mathrm{~ms}$ showing an oscillatory nature in the flow. The small amplitude velocity fluctuations are due to the above mentioned pressure reflections. At any time in the plot that the velocity is positive (above the red line), the flow is into the plenum. Peak flow reversal at the break occurs at approximately $t=216.6 \mathrm{~ms}$. Figure 15 displays the the $u$-component of velocity near the break during peak inflow into the plenum. Peak velocity, 


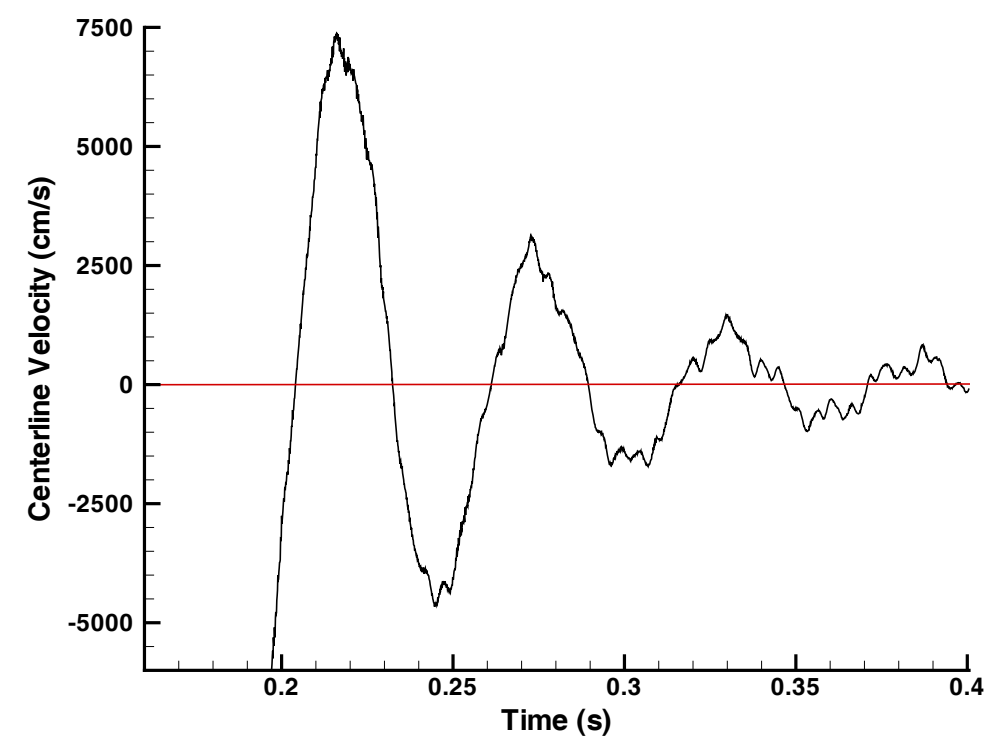

Figure 14. Centerline velocity at $x=0.0 \mathrm{~cm}$.

$u=8,510.5 \mathrm{~cm} / \mathrm{s}$, occurred along the centerline near $x=20.0 \mathrm{~cm}$ at $t=216.6 \mathrm{~ms}$. Notice that the peak velocity is inside the hot duct. This is due to the multi-dimensional effects of the reentrant flow. This simple plenum depressurization simulation indicates that, for short periods of time, there

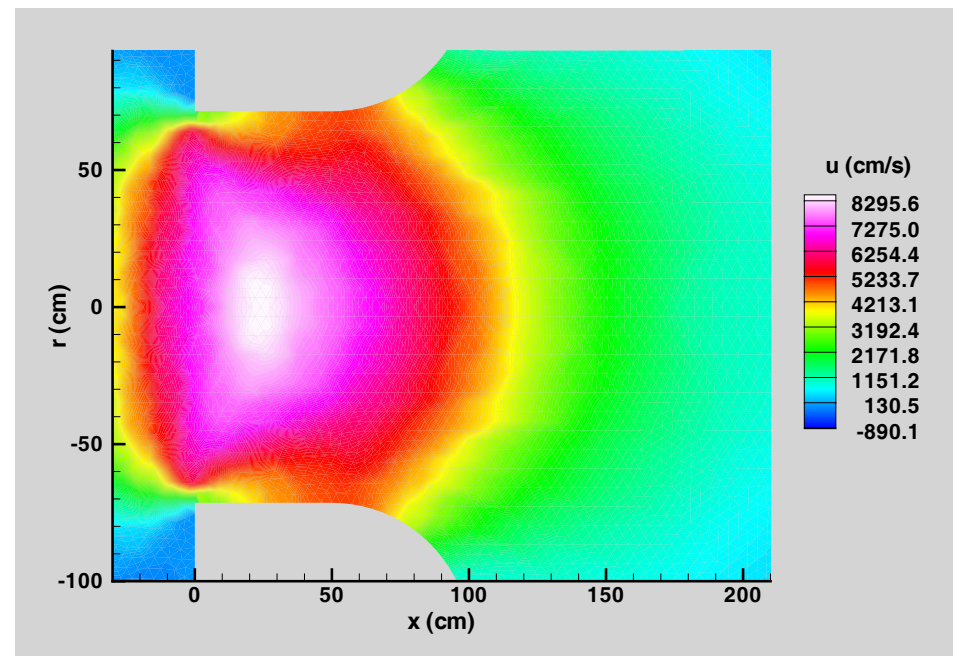

Figure 15. $u$-component of velocity near the hot duct break at the approximate moment of peak flow reversal, $t=197.9 \mathrm{~ms}$. 
is a potential for rapid flow reversal due to a Taylor wave exiting the reactor vessel resulting in the possible dynamic introduction of air inside the reactor vessel. The flow reversal phenomena is a natural characteristic of a rapid depressurization event that has not yet been considered in VHTR accident analysis. 


\section{Summary and Recommendations}

In Summary, we investigated the possibility of a rapid flow reversal into the reactor vessel due to a Taylor wave expansion after a hypothetical sudden Depressurized Loss of Forced Cooling (DLOFC) scenario in a Very High Temperature gas-cooled Reactor (VHTR). Our analysis approach started with a one-dimensional shock tube simulation to simply illustrate the development of a Taylor wave with resulting reentrant flow. Then, a simulation was performed of an idealized two-dimensional axisymmetric representation of the lower plenum of General Atomics Gas Turbine-Modular Helium Reactor (GT-MHR) subjected to a hypothetical catastrophic break of the hot duct. Our analysis shows that the short-time scale dynamics of a large depressurization event in a VHTR may have impact on subsequent air ingress and core structural performance.

Additional analysis of the possible consequences of a sudden VHTR depressurization are recommended. A logical progression of investigation steps are as follows:

1. A full two-dimensional axisymmetric reactor simulation, based upon the geometry illustrated in Figure 11(b), would be performed first. This simulation would also include an axisymmetric representation of the reactor compartment. This two-dimensional simulation would provide realistic space and time scales of a depressurization event based upon representative dimensions of the reactor and compartment. Also, the combined cross-sectional area of the two-dimensional core coolant channels, shown in Figure 11(b), has an equivalent cross-sectional area of the actual reactor flow cross-section. This would provide some insight of how the helium coolant channels in the core structure might affect rarefaction and Taylor wave formation and propagation. The Multi-component flow would be incorporated, consisting of helium and air with the initial concentrations being $100 \%$ helium in the reactor and $100 \%$ air in the reactor compartment.

2. A full three-dimensional strongly coupled multiphysics simulation should be performed next, where actual design geometries of the reactor vessel and compartment may be incorporated into the simulation. The detail of physics that could be incorporated into this simulation would only be limited by the sophistication of the software and the available computer resources. Primary physics for this simulation would include turbulent multi-component flow (defined by oxygen, nitrogen, and helium components in order to obtain a representative distribution of oxygen inside the reactor vessel) fully coupled to solid-state heat conduction and radiation transport (both neutron and photon). An all-speed flow capability would allow for a continuous simulation of high-speed depressurization into the air-filled reactor compartment (with an approximate Mach number of $M \approx 6$ in the air phase) through the natural convection phase (with a Mach number on the order of $M \approx 0.001$ ).

3. The three-dimensional simulation would not be complete with out considering the dynamic pressure loading on the core structures (fluid-structure interaction). Consider Figure 11(a) with the asymmetric location of the hot duct, the rarefaction wave would propagate asymmetrically into the reactor vessel. This could produce severe transverse loadings upon the core structure. Coupled structural mechanics analysis would provide more confidence in the structural integrity of the core. 


\section{References}

[1] General Atomics. Gas turbine-modular helium reactor (gt-mhr) conceptual design description report. GA Project No. 7658, Report 910720, San Diego, CA, July 1996.

[2] S. Ball, M. Richards, and Sergey Shepelev. Sensitivity studies of air ingress accidents in modular htgrs. Johannesburg, South Africa, October 1-4, 2006. 3rd International Topical Meeting on High Temperature Reactor Technology.

[3] United States Nuclear Regulatory Commission. Next generation nuclear plant phenomena identification and ranking tables (pirts). NRC Job Code N6376, Report NUREG/CR-6944, Vol. 6, March 2008.

[4] A.C. Kadak and T. Zhai. Air ingress benchmarking with computational fluid dynamics analysis. Nuclear Engineering and Design, 236:587-602, 2006.

[5] R.L. Löhner. Applied CFD Techniques. John Wiley \& Sons, New York, 2001.

[6] R.C. Martineau. The pcice-fem scheme for highly compressible axisymmetric flows. Computers and Fluids, 36:1259-1272, 2007.

[7] R.C. Martineau and R.A. Berry. Characteristic boundary conditions for the two-step taylorgalerkin fem. Computational Methods in Applied Mechanics and Engineering, 195:742-762, 2006.

[8] R. Moore, C. Oh, B. Merrill, and D. Petti. Meeting the thermal-hydraulic analysis needs for advanced gas reactor systems. Petten, NL, April 22-24, 2002. Conference on High Temperature Reactors. Organized by HTR-TN in cooperation with the European Nucler Society (ENS) and the IAEA International Atomic Energy Agency, Vienna (Austria).

[9] R. Moormann. Phenomenology of graphite burning in massive air ingress accidents. Johannesburg, South Africa, October 1-4, 2006. 3rd International Topical Meeting on High Temperature Reactor Technology.

[10] C.H. Oh, E.S. Kim, H.C. No, and N.Z. Cho. Experimental validation of stratified flow phenomena, graphite oxidation, and mitigation strategies of air ingress accidents. Technical report INL/EXT-06-14840, Idaho National Laboratory, Idaho Falls, Idaho, 83415, December 2008 .

[11] M.A. Saad. Compressible Fluid Flow. Prentice-Hall, London, 1985.

[12] R. Schultz, D. Nigg, A. Ougouag, W. Terry, J. Wolf, H. Gougar, G. Johnsen, D. McEligot, G. McCreery, R. Johnson, J. Sterbentz, P. MacDonald, T. Taiwo, T. Wei, W. Yang, R. Vilim, W. Pointer, and H. Khalil. Next generation nuclear plant - design methods development and validation research and development program plan. Technical report INEEL/EXT-04-02293, Idaho National Laboratory, Idaho Falls, Idaho, 83415, September 2004. 
[13] R. Schultz, A. Ougouag, D. Nigg, H. Gougar, R. Johnson, W. Terry, D. McEligot, G. Johnsen, G. McCreery, W. Yoon, J. Sterbentz, S. Krusch, T. Taiwo, T. Wei, W. Pointer, W. Yang, M. Farmer, and H. Khalil. Next generation nuclear plant - methods technical program plan. Technical report INL/EXT-06-11804, Idaho National Laboratory, Idaho Falls, Idaho, 83415, September 2006.

[14] L.I. Sedov. Similarity and Dimensional Methods in Mechanics. Academic Press, New York, 1959.

[15] K.P. Stanyukovich. Unsteady Motion of Continuous Media. Pergamon Press, New York, 1960 .

[16] G. Taylor. The formation of a blast wave by a very intense explosion. ii. the atomic explosion of 1945. Proceedings of the Royal Society of London. Series A, Mathematical and Physical Science, (1065):175-186, 1950.

[17] S.T. Zalesak. Fully multi-dimensional flux-corected transport algorithms for fluids. Journal of Computational Physics, 31(3):335-362, 1979.

[18] M.J. Zucrow and J.D. Hoffman. Gas Dynamics, volume 1. John Wiley \& Sons, New York, 1976. 


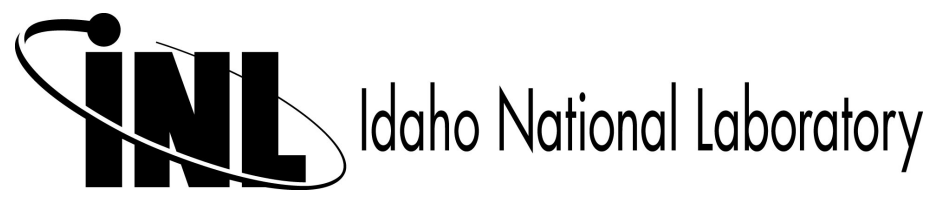

